\title{
Major Element Geochemistry of LongShan Loess Profile in the Central Shandong Mountainous regions, Northern China
}

\author{
Min Ding ${ }^{1,2 *}$,Shuzhen Peng ${ }^{1 *}$, Longjiang Mao ${ }^{3}$, Wei Zhang ${ }^{1}$, Qiuyue Zhao ${ }^{1}$ \\ ${ }^{1}$ The Key Laboratory of Tourism and Environment in Universities of Shandong, Taishan University, \\ Tai'an 271000, China \\ ${ }^{2}$ The College of Tourism and Environment, Shaanxi Normal University, Xi'an 710062, China \\ ${ }^{3}$ College of Marine Science, Nanjing University of Information Science and Technology, Nanjing 210044, China \\ *Corresponding author,Email:dingmintsjy@163.com,shuzhenpeng@sohu.com
}

Received 16 July 2017

Accepted 13 August 2017

\begin{abstract}
In this paper, the major elements of the Longshan loess profile on the northern piedmont zones and intermountain valleys of mountainous regions in central Shandong Province in northern China, have been systematically tested and been compared with the YHC loess in the Loess Plateau to reveal the geochemical characteristics and material sources of LS loess. It is found that the average chemical composition of Shandong LS profile is similar to that of typical loess at $\mathrm{YHC}$ profile. The CIA, $\mathrm{Na}_{2} \mathrm{O} / \mathrm{K}_{2} \mathrm{O}$ and $\mathrm{Al}_{2} \mathrm{O}_{3}-\mathrm{CaO}+\mathrm{Na}_{2} \mathrm{O}-\mathrm{K}_{2} \mathrm{O}$ triangles show that the LS loess is in moderate weathering stage and the chemical weathering degree is higher than that of the YHC profile in the Loess Plateau, but it is still in the $\mathrm{Na}, \mathrm{Ca}$ removal of stage. Element activity sequence at the LS profile is $\mathrm{Ca}>\mathrm{Na}>\mathrm{Mg}>$ $\mathrm{Si}>\mathrm{Al}>\mathrm{K}>\mathrm{Fe}$, and Element activity capacity at $\mathrm{LS}$ profile is higher than that of at $\mathrm{YHC}$ profile. The ratio of $\mathrm{TiO}_{2} /$ $\mathrm{Al}_{2} \mathrm{O}_{3}$ and $\mathrm{K}_{2} \mathrm{O} / \mathrm{Al}_{2} \mathrm{O}_{3}$ of the material source index clearly distinguishes LS loess and $\mathrm{YHC}$ loess, and it is concluded that the LS loess has different source from the loess plateau loess. It is not the result of dust storm direct from the northwest of China; otherwise, the Yellow River sediments and the North China Plain Material nearby may be its main sources when it was colder and drier during the glacial period. CIA and $\mathrm{K}_{2} \mathrm{O} / \mathrm{Na}_{2} \mathrm{O}$, and the migration rate of $\mathrm{Fe}, \mathrm{Al}, \mathrm{K}$ and $\mathrm{Na}$ is restored to the depositional environment of research. The winter monsoon in the late glaciation is strong and the chemical weathering is weak. In the early Holocene winter monsoon is weakened and the chemical weathering is enhanced. In the middle of Holocene, the summer monsoon dominated and the chemical weathering is strongest; in late Holocene, the climate deteriorated again, the chemical weathering is weakened.
\end{abstract}

Key words: loess in Shandong; elemental geochemistry; weathering intensity; environmental significance; material source

\section{Introduction}

Element geochemistry plays an important role in studying Quaternary sediments (Guo, et al. 2009; Huang, et al. 2009; Hao, et al. 2010; Taylor. 1985). In the process of eolian transport, eolian accumulation and soil formation, It is accompanied by the migration, transformation and enrichment of elements (Guo, et al.
2009; Huang, et al. 2009). Therefore, the composition and evolution of elements have unique advantages in regional environmental reconstruction and provenance studies (Guo, et al. 2009; Huang, et al. 2009), many studies on major elements have been carried out about loess (Peng, et al. 2001; Xiong, et al. 2008; Chen, et al. 2001; Ding, et al. 2011) in the Loess Plateau and its surroundings (Huang, et al. 2009; Hao, et al. 2010; Li, 
et al. 2013; Li, et al.2016; Li, et al. 2007; Zhang, et al. 2013; Cao, et al. 1987). The Loess of Shandong is located in the link between northern and Southern Loess, and plays a key role in regional environmental evolution and Global Monsoon reconstruction. In the past, traditional stratigraphy, sedimentology and other means have been used to study the causes of loess (Cao, et al. 1987; Zhang.1995; Zhao, et al. 1996), material sources (Peng, et al. 2007; Peng, et al. 2011; Xu, et al. 2014) and climate change (Li. 1987; Ding, et al. 2011), element geochemical research has achieved certain results (Diao. 1994; Peng, et al. 2016; Xu, et al. 2016; Ni.2015), but the high-resolution research is still relatively rare. Enriching and perfecting the data of loess elements in Shandong will undoubtedly help to reveal the internal relationship between the Loess Plateau and the surrounding loess, and help to reveal the process of regional environmental change. This paper systematically analyzes the major geochemical characteristics of the Longshan loess profile in the central Shandong mountainous regions in northern China, and compares it with typical loess sections such as YHC profile in the Loess Plateau to reveal its chemical weathering characteristics, migration laws and material sources. Material source and transport path and dust accumulation law will contribute to the prediction of modern dust storm risk.

\section{Materials and methods}

\subsection{Study area and profile characteristics}

The study area is located at the central Shandong Mountains of North China Plain (Fig.1), it is covered with the alluvial flood plain only along the Yellow River, the rest mostly consists of the hills and low mountains, elevating between $200 \mathrm{~m}$ and $1545 \mathrm{~m}$. The region has a warm temperate and semi-humid monsoon climate with distinct season, prevailing northwesterly wind in winter and southeasterly wind in summer, respectively. Annual temperature and precipitation are about average 12.6-14.5 ${ }^{\circ} \mathrm{C}$ and 615.3-793.9 mm (Peng et al., 2016). Thick loess deposits in central Shandong Mountains mainly spread in the east-west direction along the northern piedmont regions of the central Shandong Mountains (Fig.1a).

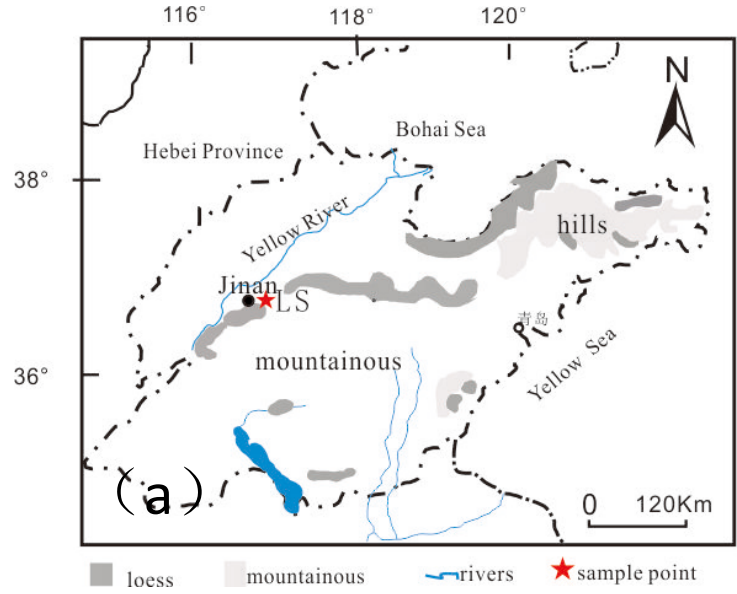

(a) the locations for the research areas and the sampling points

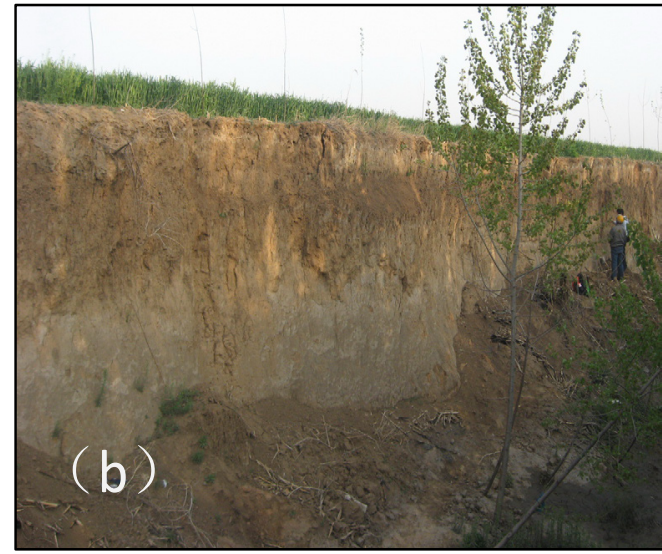

(b) the photos of the sections

Figure.1. Research areas, ampling point location and the profile of field picture

The section of Longshan is located in Shandong (hereinafter referred to as LS) $\left(117^{\circ} 21^{\prime} 46.2^{\prime \prime} \mathrm{E}\right.$, $36^{\circ} 43^{\prime} 59.4^{\prime \prime} \mathrm{N}$ ), the exposed depth is about $4 \mathrm{~m}$ (bottom not seen), the elevation is $56 \mathrm{~m}$ (Fig. 1b). 120 samples are abtained continuously from upside to downside with an interval of $2.5 \mathrm{~cm}$. The depth of sampling is $3 \mathrm{~m}$. After the field profile morphological characteristics observation and ${ }^{14} \mathrm{C}$ dating (data published elsewhere), it is determined that the section has formed since the last Glacial, we can divide the LS profile into the following layers: $\mathrm{L}_{1}(190 \mathrm{~cm}$ below) sediments formed in the last glacial period, it is yellow, clay silt. Lt $(190 \sim 160 \mathrm{~cm}$ deep) is the transition layer, which formed in the early Holocene, it is grey yellow; $\mathrm{S}_{0}(160 \sim 50 \mathrm{~cm}$ deep $)$ formed in Mid-Holocene, it is brown ancient soil, texture is hard, the structure is prismatic; $\mathrm{L}_{0}(50 \sim 0 \mathrm{~cm}$ deep $)$, is the modern dust accumulation layer which formed in the 
late Holocene, it is orange and sandy soil. The Loess Plateau is the result of wind transport and accumulation from the northwest desert and Gobi. The YHC section of the Loess Plateau is chosen as the representative of the northwest desert and Gobi sediments The profile of Yaohe Village (hereinafter referred to as YHC) in Baishui, Shanxi is located on the plateau $\left(109^{\circ} 29^{\prime} 4.7^{\prime \prime} \mathrm{E}\right.$ , $35^{\circ} 15^{\prime} 57.3^{\prime \prime} \mathrm{N}$, the elevation is $960 \mathrm{~m}$ ), and is in the west of the LS section in Shandong, the two section latitudes match each other. The layer for the YHC section is clear, it is divided from top to bottom as: the surface layer (MS), the modern loess layer $\left(\mathrm{L}_{0}\right)$, the paleosol layer $\left(\mathrm{S}_{0}\right)$, the Malan Loess layer $\left(\mathrm{L}_{1}\right)$, Baishui belongs to the warm temperature semi-arid climate, the annual average temperature and the annual precipitation in Baishui are $11.4^{\circ} \mathrm{C}$ and $577.8 \mathrm{~mm}$ respectively.

\subsection{The experiment method}

The determination for the chemical element is applied with the PW2403 X-Ray Fluorescence Spectrometer produced by the company of Panalytical from the Netherlands. We grind the natural dried samples until the diameter of the particle is smaller than 200 eyes, and then weigh for $4 \mathrm{~g}$ of the samples with the use of the method for chrome acid to press the tablets on the pressure protot of YY-60; put the samples after the press of tablets into the sample cup by sequence, conduct the determination for the content of the chemical elements by the PW2403 X-Ray Fluorescence Spectrometer. In order to control the stability of the measurement and the error, the national standard samples of GSS-1 and GSD-12 are added in the process of measurement for the control, the error is controlled within $5 \%$.

\section{The result of the experiment}

As it is indicated in Fig.2 and Fig.3, the major elements in the LS section of Shandong have the following characteristics:

- the composition of major elements in LS section as follows, the content of $\mathrm{SiO}_{2}$ is the highest which is $52.07 \% \sim 65.53 \%$, the content of $\mathrm{Al}_{2} \mathrm{O}_{3}$ is $12.36 \% \sim 15.85 \%$, the content of $\mathrm{Fe}_{2} \mathrm{O}_{3}$ is $3.90 \% \sim 6.63 \%$, the content of $\mathrm{K}_{2} \mathrm{O}$ is $1.96 \% \sim 2.66 \%$, The average content of the four main chemical components in the LS section which are $\mathrm{SiO}_{2}, \mathrm{Al}_{2} \mathrm{O}_{3}, \mathrm{Fe}_{2} \mathrm{O}_{3}, \mathrm{~K}_{2} \mathrm{O}$, the average content of the four reaches $82.22 \%$
(69.78\% 99.30\%), the composition sequence for the average content of the elements is $\mathrm{SiO}_{2}$ $(59.30 \%)>>\mathrm{Al}_{2} \mathrm{O}_{3}(14.01 \%)>\mathrm{Fe}_{2} \mathrm{O}_{3}(5.14 \%)>$ $\mathrm{CaO}(4.32 \%)>\mathrm{K}_{2} \mathrm{O}(2.40 \%)>\mathrm{MgO}(2.04 \%)>$ $\mathrm{Na}_{2} \mathrm{O}(1.10 \%)>\mathrm{TiO}_{2}(0.68 \%)$. It has the characteristics of uniform composition of wind loess such as YHC section on Chinese Loess Plateau.

- The vertical variation trend of the major elements such as $\mathrm{Al}_{2} \mathrm{O}_{3}, \mathrm{Fe}_{2} \mathrm{O}_{3}, \mathrm{~K}_{2} \mathrm{O}$ and $\mathrm{TiO}_{2}$ in the LS profile is basically the same, and they are relatively enriched in the paleosol layer $\left(\mathrm{S}_{0}\right)$, and relatively deficient in the loess layer $\left(\mathrm{L}_{0}, \mathrm{~L}_{1}, \mathrm{~L}_{\mathrm{t}}\right)$. The change trend of $\mathrm{Na}_{2} \mathrm{O}$ is opposite to that of $\mathrm{Al}_{2} \mathrm{O}_{3}, \mathrm{Fe}_{2} \mathrm{O}_{3}, \mathrm{~K}_{2} \mathrm{O}$ and $\mathrm{TiO}_{2}$. The content of $\mathrm{Na}_{2} \mathrm{O}$ in paleosol $\left(\mathrm{S}_{0}\right)$ is lowest, and the content is higher in loess layer $\left(\mathrm{L} 0, \mathrm{~L}_{1}\right.$ and $\left.\mathrm{Lt}\right)$.

- $\mathrm{SiO}_{2}$ and $\mathrm{CaO}$ appear with highly significant negative correlation $(\mathrm{R}=-0.901)$ which is the same as the relationship with the two disclosed in the YHC section in the central shaaxi plain (M. Ding, et al.2011) and the ZLTC section in the southern Shanxi ( $\mathrm{Li}$, et al. 2013). $\mathrm{CaO}$ is mainly present in the form of silicate and $\mathrm{CaCO}_{3}$, and the $\mathrm{CaO}$ content is low and the $\mathrm{SiO}_{2}$ content is high in $\mathrm{S}_{0}$ and $\mathrm{L}_{0}$, and they are opposite in $\mathrm{L}_{\mathrm{t}}$ and $\mathrm{L}_{1}$.

- The distribution of the constant elements of the LS profile is related to the geochemical characteristics of the elements and the soil environment. In addition to $\mathrm{CaO}$ (coefficient of variation of 0.72 ), the vertical coefficient of variation $(\mathrm{CV})$ of other major elements is less than 0.25 , and the coefficient of variation is $\mathrm{Ti}(0.02)$ and $\mathrm{Al}(0.05)$. The results show that the material composition of LS loess-paleosol sequence in Shandong has the characteristics of uniform composition of wind loess.

- It can be known from image 3, compared with UCC, the LS section of Longshan has the characteristics of poor $\mathrm{Na}$ and rich $\mathrm{Ti}$, the content of other elements is similar. Compared with the different layers of LS section, the dropping $\mathrm{Na}, \mathrm{K}$ and the rich $\mathrm{Ti}$ is almost at the same degree which means the characteristics of the source area; the difference between the layers of $\mathrm{Ca}$ is obvious. $\mathrm{L}_{1}$, $\mathrm{L}_{\mathrm{t}}$ are in rich of $\mathrm{Ca}$ in an apparent way, while $\mathrm{S}_{0}$, $\mathrm{L}_{0}$ drop $\mathrm{Ca}$ in an apparent way, it is the reason that the element $\mathrm{Ca}$ obviously migrated after the 
accumulation of wind dust. Compared with the YHC section, in the paleosol layer of $\mathrm{S}_{0}$ of the LS section, the elements of $\mathrm{Ca}, \mathrm{Mg}$ and $\mathrm{Na}$ are relatively lost, especially $\mathrm{Ca}$ of which the loss is the most obvious one; $\mathrm{Fe}, \mathrm{Al}, \mathrm{K}$ and $\mathrm{Si}$ are relatively concentrated, the concentration of $\mathrm{Fe}$ and $\mathrm{Al}$ is relatively obvious. In the loess layer of $\mathrm{L}_{1}$, the element of $\mathrm{Mg}, \mathrm{Na}$ are relatively lost, $\mathrm{Ca}$, $\mathrm{Fe}$ and $\mathrm{Al}$ are relatively concentrated.

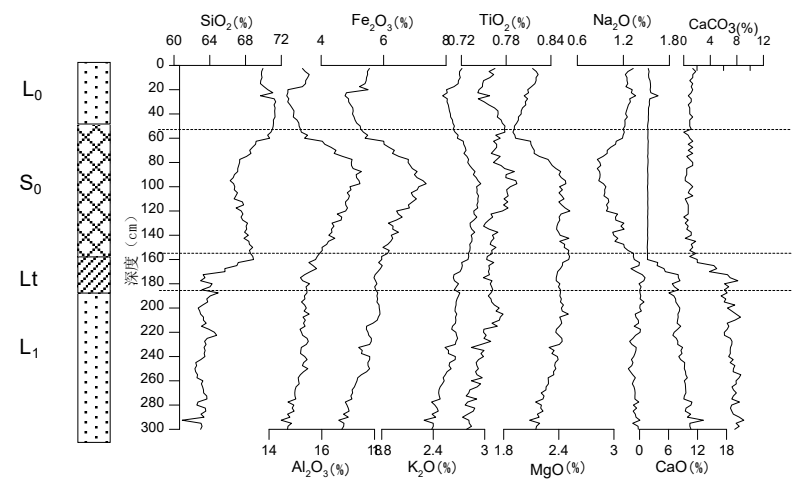

Fig. 2. Change curves of major elements content and $\mathrm{CaCO}_{3}$ at LS loess-soil profile in Shandong province

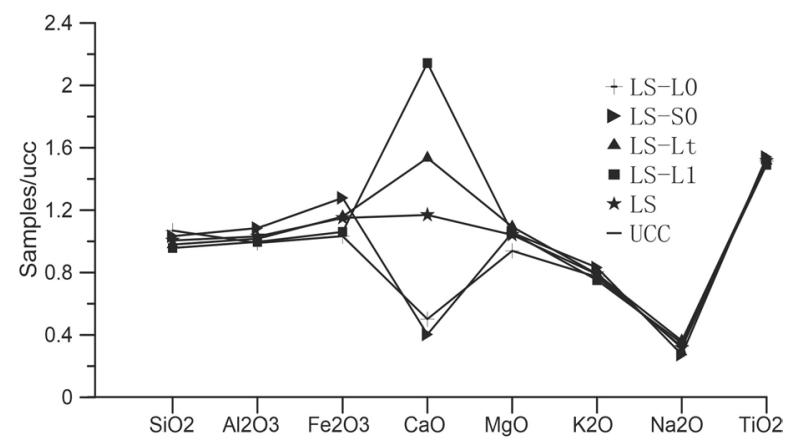

Fig. 3. Curves of major elements standardized by UCC at LS profile

In brief, the compositions of major elements in both LS section and YHC section are quite similar; compared with UCC the difference is mainly caused by weathering. It is indicated that the LS profile is characterized by eolian deposits and is preliminarily judged to be mainly a eolian. This is consistent with previous findings (Peng, et al. 2016; Xu, et al. 2016).

\section{The discussion for the problems}

\subsection{The characteristics of weathering $(\mathrm{CIA}, \mathrm{Na} / \mathrm{K}$ and $A-C N-K)$}

The A-CN-K $\left(\mathrm{Al}_{2} \mathrm{O}_{3}-\mathrm{CaO} *+\mathrm{Na}_{2} \mathrm{O}-\mathrm{K}_{2} \mathrm{O}\right)$ triangle reflects the trend of chemical weathering, the changes in principal composition and mineralogy during chemical weathering, and the palaeo climate environment during sediment deposition (Gu. 1999; Wang, et al. 1995; Gallet, et al. 1982; Nesbitt, et al. 1980 and 1982). In Figure $4 \mathrm{a}$, the distribution of data points of LS profile are in the above the plagioclase-feldspar baseline, its weathering trend line substantially parallel to the A-CN line, just lying on the line of continental crust UCC and terrigenous shale PAAS connection, close to the plagioclase and not reach the side of A-K line, which implies that the loess feldspar mineral chemical weathered weakly, and experienced dropping $\mathrm{Na}$ and $\mathrm{Ca}$, but potassium feldspar almost no changes. So, it may still be in the early stages of chemical weathering (J.Chen, et al. 2001), weathering products are mainly kaolinite, illite and montmorillonite. The loss rate of $\mathrm{Na}$ and $\mathrm{Ca}$ is the lowest in $\mathrm{L}_{1}$ and the highest in $\mathrm{S}_{0}$. in addition, we select the $\mathrm{S}_{0}$ with the strongest soil formation and $\mathrm{L}_{1}$ with the weakest soil formation to project point on the triangle of A-CN-K digram, the data points of LS in Shandong province is closer to point $\mathrm{A}$,

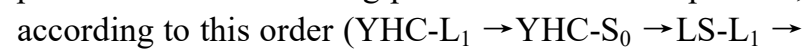
LS- $\mathrm{S}_{0}$ ), the degree of weathering is enhanced, generally the strength of dropping $\mathrm{Ca}$ and $\mathrm{Na}$ of loess in LS section is higher than that of the YHC section in Loess Plateau (Fig. 4b). The data points of both LS section and YHC section are concentrated and distributed at $\mathrm{UCC} \rightarrow$ PAAS chemical weathering trend line (parallel with the connection line of $\mathrm{A}-\mathrm{CN}$ ), this characteristics again explains that LS section is to some extent the same with the YHC section of the Loess Plateau, which both are originated from the wide upper continental crust with a certain mixing before the sedimentation. 


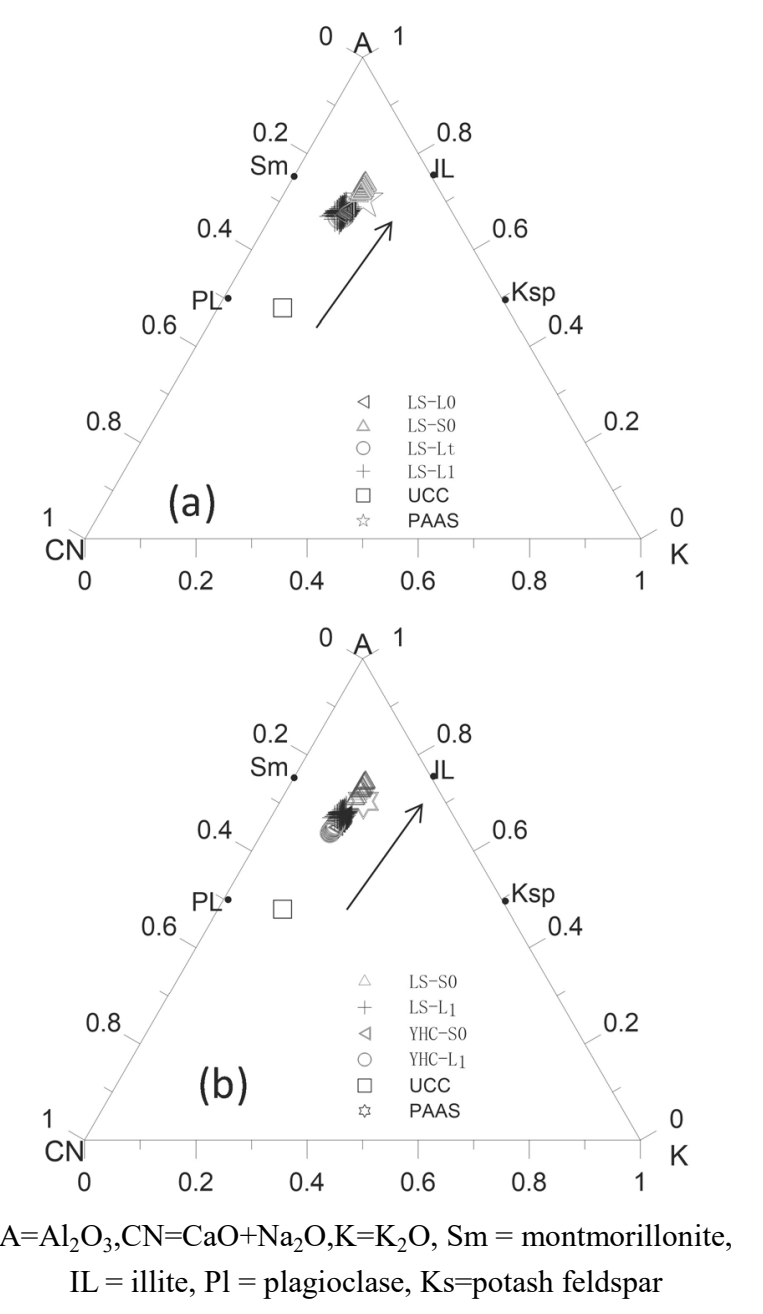

Fig. 4. LS(a) and other dust deposits(b) plotted in A - CN - K ternary diagram

The molecular ratio of the elements reduces the impact from the elements of disturbance to some extent which can effectively disclose the weathering degree for the sediments, CIA and $\mathrm{Na}_{2} \mathrm{O} / \mathrm{K}_{2} \mathrm{O}$ is the commonly used alteration index for the chemical weathering. The chemical index of alteration (CIA) may effectively indicate the degree of weathering from the feldspars into the clay mineral, the larger the value is, and the stronger the degree of the weathering reflected will be. The calculation formula of CIA is: $\mathrm{CIA}=\left[\mathrm{Al}_{2} \mathrm{O}_{3} /\left(\mathrm{Al}_{2} \mathrm{O}_{3}+\mathrm{CaO} *+\mathrm{K}_{2} \mathrm{O}+\mathrm{Na}_{2} \mathrm{O}\right)\right] \times 100$, in the formula: all are the mole numbers for the oxide molecules, of which $\mathrm{CaO}^{*}$ is the mole number in the mineral of silicate. All the calculation methods for the value of $\mathrm{m}_{\mathrm{CaO}}$ in this article are as follows: when the mole number of $\mathrm{CaO}$ is larger than $\mathrm{Na}_{2} \mathrm{O}, \mathrm{m}_{\mathrm{CaO}}=\mathrm{m}_{\mathrm{Na} 2 \mathrm{O}}$, when it is smaller than $\mathrm{Na}_{2} \mathrm{O}$, then $\mathrm{m}_{\mathrm{CaO}}{ }^{*}=\mathrm{m}_{\mathrm{CaO}}$ (S.M.McLennan.1993). Research finds out that the value of CIA is between $50 \% \sim 65 \%$ which reflects the degree of chemical weathering of lower level under the condition of cold climate; when the value of CIA is between $65 \% \sim 85 \%$, it reflects the strength of the chemical weathering of medium level under the warm and humid climate; when the value of CIA is between $85 \% \sim 100 \%$, it reflects the strength of the chemical weathering is very strong under the condition of subtropical climate. $\mathrm{Na}_{2} \mathrm{O} / \mathrm{K}_{2} \mathrm{O}$ is also the effective index for the degree of weathering of feldspar which is negatively related to the soil formation of weathering.

The CIA of LS section varies between 66.3 74.5, the average value is 69.1 . The weathering sequence for the different layers of the section is $\mathrm{S}_{0}(71.5)>\mathrm{L}_{0}(68.2)$ $>\mathrm{L}_{1}(67.7) \approx \mathrm{Lt}(67.2)>>\mathrm{UCC}$, it means that the whole section of LS in Shandong province is at the medium weathering stage. While the YHC section of the Loess Plateau which is at the transition stage of lower weathering and medium weathering, the average value of CIA is $65.6(63.7 \sim 67.7)$, the strongest weathering layer is $\mathrm{S}_{0}$ which is close to the medium weathering degree. Compared with those on the same layer, $\mathrm{CIA}_{\mathrm{LS}}>\mathrm{CIA}_{\mathrm{YHC}}$. It explains that the weathering degree of LS section is obviously higher than the YHC section in the Loess Plateau., and the $\mathrm{L}_{\mathrm{t}}$ with the weakest weathering in the LS section (CIA is 67.2) is roughly the same as the $\mathrm{S}_{0}$ with the strongest weathering in the YHC section (CIA is 66.5) in the weathering degree. $\mathrm{Na}_{2} \mathrm{O} / \mathrm{K}_{2} \mathrm{O}$ ratio in both the LS and $\mathrm{YHC}$ section shows obvious the systematic changes in cycle which is lower in the paleosol layer and higher in loess layer, and has a good negative correlation with the numerical value of CIA. The weathering sequence it expressed is similar with that of CIA. The average value of $\mathrm{Na}_{2} \mathrm{O} / \mathrm{K}_{2} \mathrm{O}$ for the LS section is $0.71(0.46 \sim 0.94)$, the lowest value appears in the paleosol and the highest value in $\mathrm{L}_{1}$, the sequence for the claying degree of LS is $\mathrm{S}_{0}(0.58)>\mathrm{L}_{0}$ $(0.73)>\mathrm{L}_{\mathrm{t}}(0.80) \approx \mathrm{L} 1(0.81)$, the one layer with the strongest claying of YHC is also $\mathrm{S}_{0}(0.81)$, the second is $\mathrm{L}_{0}(0.86)$, the claying degree of $\mathrm{L}_{1}$ is the lowest, $\mathrm{Na}_{2} \mathrm{O} / \mathrm{K}_{2} \mathrm{O}$ is 0.94 . Compared with the two sections, the $\mathrm{Na}_{2} \mathrm{O} / \mathrm{K}_{2} \mathrm{O}$ value of the LS section is obviously smaller than that of the corresponding layer of YHC section in the Loess Plateau. It is consistent with the extent of weathering revealed by CIA. In conclusion, the LS section in Shandong has experienced stronger feldspar 
weathering. It is completely consistent with the weathering degree disclosed by CIA. In short, the LS section in Shandong has experienced a stronger feldspar weathering than YHC section on the Loess Plateau.

The CIA of the LS section (69.1) is slightly lower than that of the Xiashu loess in the southern china whose CIA is 70.45 (the annual average temperature is $15.4^{\circ} \mathrm{C}$, the precipitation is $\left.450 \mathrm{~mm}\right)(\mathrm{Li}$, et al. 2007), higher than that of Shanxi Luochuan section whose CIA is 62.5 (the annual average temperature is $9.2^{\circ} \mathrm{C}$, the precipitation is $620 \mathrm{~mm}$ ) (Huang, et al. 2009), and Shanxi Xiangfen section whose CIA is 63.6 (the annual average temperature is $11.5^{\circ} \mathrm{C}$, the precipitation is $550 \mathrm{~mm}$ ) (Li, et al. 2013), and Shanxi YHC section whose CIA is 65.5 (the annual average temperature is $11.4^{\circ} \mathrm{C}$, the precipitation is $577.8 \mathrm{~mm}$ ) (Ding, et al. 2011), which are slightly higher than the loess at Zhoujiagou, Liaonan whose CIA is 66.1 (the annual average temperature is $9.6^{\circ} \mathrm{C}$, the precipitation is $708 \mathrm{~mm}$ ) (Zhang, et al. 2013). The weathering degree of LS section in Shandong is slightly lower than that of southern loess, higher than that of western Loess on Loess Plateau and northeastern Liaoning Loess, which is not so hot as that in southern China, but wetter and warmer than that of the west and warmer than Liaonan in the north east. And which is corresponding with large bio-climatic conditions. It is shown that the dust deposits are mixed and the parent material impact is small, and the CIA is mainly controlled by the change of climate change, especially the precipitation (J.X.Cao, et al. 1987; Z.L.Zhang. 1995; S.L.Zhao, et al. 1996; S.Z.Peng, et al. 2007). However, the CIA reveals the comprehensive weathering information of dust accumulation, including the source, the process of sorting and environmental changes in the sedimentary area, such as the degree of weathering of the LS section (CIA is 69.1) is significantly higher than that of Shandong Pingyin loess (CIA $42.9 \sim 63.3$ ) (Xu, et al. 2016) and the Miaodao Islands (59.7, averages of 4 profiles) (Ni. 2015), indicating that the apparent differences in CIA under similar climatic conditions are related to material source and particle size sorting, Significant differences in CIA in Shandong may be caused by different material sources.

\subsection{The activity of the elements}

In conclusion, different major elements have different geochemical behaviors in the process of loess formation, and are closely related to the environment of the soil formation t. Most elements have particle size sorting effect. In addition, they are impacted by the leaching deposition of element $\mathrm{Ca}$. Absolute content of major elements does not reflect its true geochemical properties (Li, et al. 2007; Zhang, et al. 2013).

Elements in LS and YHC profile were not subjected to acid-soluble treatment before the test. In order to eliminate the influence of carbonate leaching, the change rate of other elements in the sample was calculated by using the stability element $\mathrm{Ti}$ as reference to obtain the transportation and concentration degree of the elements. Using the method proposed by Gallet et al. (S.Gallet, et al. 1982). the calculation formula is: $\Delta(\%)$ $=\left[\left(\mathrm{X}_{(\mathrm{s})} / \mathrm{I}_{(\mathrm{s})}\right) /\left(\mathrm{X}_{(\mathrm{L}} / \mathrm{I}_{(\mathrm{L})}\right)-1\right] \times 100$; in the section of LS and YHC, we select the Ti with the smallest coefficient of variation as the reference standard for the calculation of the migration rate of the elements in the other soil layer of the paleosol relative to $\mathrm{L}_{1}$, of which $\mathrm{X}_{(\mathrm{s})}, \mathrm{I}_{(\mathrm{s})}$ represents the content of element $\mathrm{X}$ and the reference element I respectively, $\mathrm{X}_{(\mathrm{L})}, \mathrm{I}_{(\mathrm{L})}$ represents the content of the above stated elements in the Malan Loess $\left(\mathrm{L}_{1}\right)$ respectively (because the parent material of the two sections cannot be known before the soil formation, this article will consider $\mathrm{L}_{1}$ with the weak weathering degree as the parent material). When $\Delta<0$, it explains that element $\mathrm{X}$ is migrated out in this layer compared with the reference element; when $\Delta>0$, it represents its relative concentration.

For the observation in the wild field, the soil formation of $\mathrm{S}_{0}$ is the strongest; its difference with $\mathrm{L}_{1}$ is the largest for which it can best show the difference of activity for the elements in the two sections. Compared with the $\mathrm{L}_{1}$, element migration rate in $\mathrm{S}_{0}$ in the section LS and YHC has the following characteristics (Fig. 5): element $\mathrm{Ca}, \mathrm{Na}$ and $\mathrm{Mg} \Delta<0$, all of them are leaching relative to $\mathrm{L}_{1}$, while element $\mathrm{K}, \mathrm{Fe}, \mathrm{Al} \Delta>0$, all are relatively concentrated. The activity order of the elements in the two sections is basically the same as that of $\mathrm{Ca}>\mathrm{Na}>\mathrm{Mg}>\mathrm{Si}>\mathrm{Al}>\mathrm{K}>\mathrm{Fe}$. But the activity capability of the elements in the two sections (indicated with the migration rate) is not the same apparently, the activity of the elements in LS section is higher than that in the section of YHC, particularly, in the LS section, element migration rate $\mathrm{Ca}>\mathrm{Na}>20 \%$, which it reaches 
the strong activity stage, element migration rate only $\mathrm{Ca}>20 \%$ at the YHC section, all the other elements reach no more than $10 \%$.

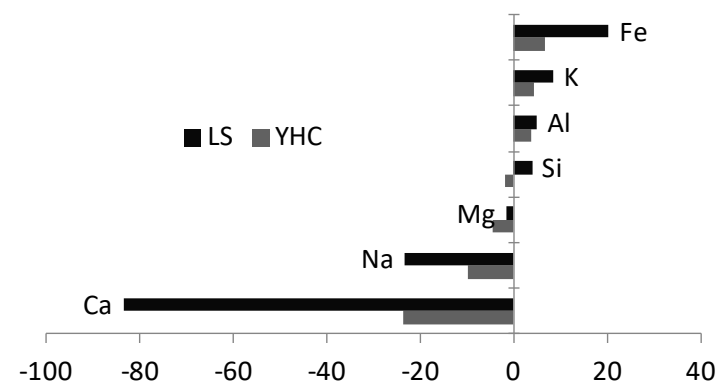

Fig. 5. Migration ratios of major elements of the LS and YHC profile relative to the stable element $\mathrm{Ti}$

Nesbitt etc. divided the process of chemical weathering into the early stage of dropping $\mathrm{Na}, \mathrm{Ca}$, the middle stage of dropping $\mathrm{K}$ and the late stage of dropping Si in accordance with the activity sequence of the elements. According to the geochemical characteristics of element migration for LS and YHC, both the section of LS in Shandong and the YHC in the Loess Plateau have not entered the stage of dropping $\mathrm{K}$ and $\mathrm{Si}$, they are still at the stage of dropping $\mathrm{Na}$ and $\mathrm{Ca}$. the loss rate of $\mathrm{Na}$ and $\mathrm{Ca}$ in the LS section is higher than that of YHC section on the Loess Plateau, it explains that the LS section has experienced the stronger weathering process than that of YHC section on loess plateau which is the same as the result CIA and $\mathrm{A}-\mathrm{CN}-\mathrm{K}$ ternary diagram have disclosed.

\subsection{Material source}

The ratio of $\mathrm{TiO}_{2} / \mathrm{Al}_{2} \mathrm{O}_{3}$ can be used to trace the material source (Hao, et al. 2010; Peng, et al. 2016). Al, $\mathrm{Ti}$ are relatively stable in the loess which are often used as the standard elements, $\mathrm{Al}$ often is stable existing in the form of oxide or aluminosilicate in nature. $\mathrm{Ti}$ is contained in extremely stable rutile and ilmenite, and it is difficult to migrate in the epigenetic environment (Hao, et al. 2010; Wang, et al. 1995). K elements are mainly present in potassium feldspar and mica, although it is easy to be weathered compared with $\mathrm{Al}$ and $\mathrm{Ti}$, but it is very easy to be absorbed by the clay due to the large radius of $\mathrm{K}$ ion, obvious migration can only occur in the soil with strong weathering. The research in the article afore discovered that the weathering degree of both LS section in Shandong and the YHC section on the Loess Plateau have not reached the senior weathering strength. $\mathrm{K}_{2} \mathrm{O} / \mathrm{Al}_{2} \mathrm{O}_{3}$ is suitable for the two sections to trace the source. In this paper, $\mathrm{TiO}_{2} / \mathrm{Al}_{2} \mathrm{O}_{3}$ and $\mathrm{K}_{2} \mathrm{O} / \mathrm{Al}_{2} \mathrm{O}_{3}$ were used to identify the source of LS in Shandong and select the $\mathrm{L}_{1}$ layer with the weakest weathering to conduct.

The trace index plot of $\mathrm{TiO}_{2} / \mathrm{Al}_{2} \mathrm{O}_{3}$ and $\mathrm{K}_{2} \mathrm{O} / \mathrm{Al}_{2} \mathrm{O}_{3}$ in the section of LS and YHC are distributed as it is shown in Fig. 6, they are distributed in two different areas apparently. The value of $\mathrm{TiO}_{2} / \mathrm{Al}_{2} \mathrm{O}_{3}$ for the LS section in Shandong province is smaller than that of the YHC section on the Loess Plateau, most of the value of $\mathrm{TiO}_{2} / \mathrm{Al}_{2} \mathrm{O}_{3}$ in LS section is between $0.060-0.065$, the data for YHC section is between 0.066 0.069; the distribution of $\mathrm{K}_{2} \mathrm{O} / \mathrm{Al}_{2} \mathrm{O}_{3}$ on the LS section in Shandong is very scattered $(0.172 \sim 0.190)$, while the distribution of $\mathrm{K}_{2} \mathrm{O} / \mathrm{Al}_{2} \mathrm{O}_{3}$ for $\mathrm{YHC}$ on the Loess Plateau is comparatively concentrated $(0.188 \sim 0.193)$, and the value of $\mathrm{K}_{2} \mathrm{O} / \mathrm{Al}_{2} \mathrm{O}_{3}$ on the $\mathrm{LS}$ section is lower than that of the YHC section. It explains that the material source of the LS loess in Shandong is not consistent with the YHC section material source on the Loess Plateau, it is not directly blowming from the northwest area in the pattern of dust storm. As the study before, the $\mathrm{K}_{2} \mathrm{O} / \mathrm{Al}_{2} \mathrm{O}_{3}$ ratio of Yellow river sediments is lower than the ratio of loess from Chinese Loess Plateau is due to the loss of Illite, Smectilte, mica and other clay minerals comminuting during fluvial transport (Peng.2016). K often is hosted in Illite, Smectilte, mica and other clay minerals, the loss of $\mathrm{K}$ leads to decrease of the ratio $\mathrm{K}_{2} \mathrm{O} / \mathrm{Al}_{2} \mathrm{O}_{3}$. The value of $\mathrm{K}_{2} \mathrm{O} / \mathrm{Al}_{2} \mathrm{O}_{3}$ on the LS section is lower as that of Yellow river sediments. It is speculated that LS loess is coming from the sediment of the Yellow River and north plain transported by wind transport. 


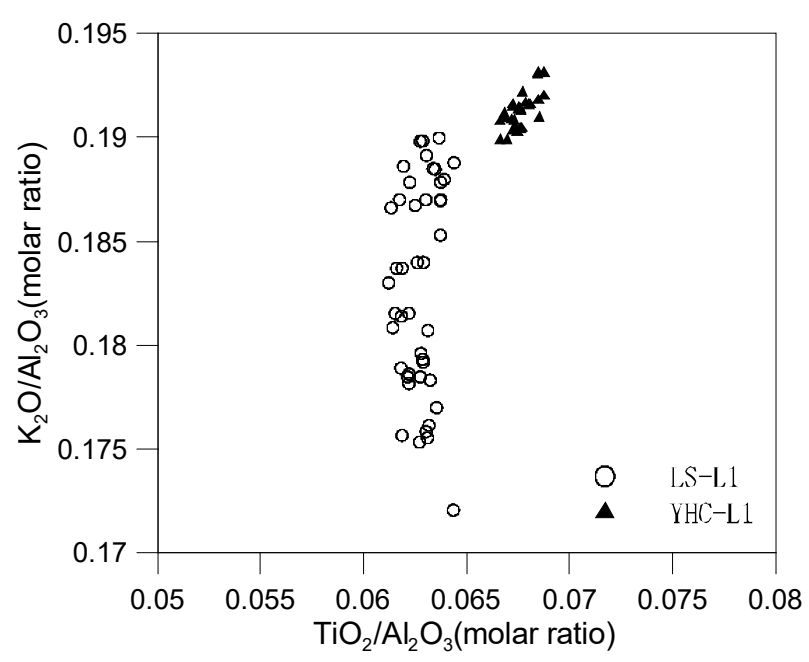

Fig. 6. The trace index plot of $\mathrm{TiO}_{2} / \mathrm{Al}_{2} \mathrm{O}_{3}$ vs. $\mathrm{K}_{2} \mathrm{O} / \mathrm{Al}_{2} \mathrm{O}_{3}$

\subsection{Environment reconstruction}

The migration rate of elements is to eliminate the impact of the parent material, it is the reliable index that directly discloses the difference of environment for sedimentation, CIA and $\mathrm{K}_{2} \mathrm{O} / \mathrm{Na}_{2} \mathrm{O}$ disclose the weathering strength, it is often used as the substitute index for the recovery of the environment. So, CIA and $\mathrm{K}_{2} \mathrm{O} / \mathrm{Na}_{2} \mathrm{O}$, and the migration rate of $\mathrm{Fe}, \mathrm{Al}, \mathrm{K}$ and $\mathrm{Na}$ are effectively used to restore the depositional environment of LS section region (Fig.7).

$\mathrm{L}_{1}(190 \mathrm{~cm} \sim 300 \mathrm{~cm}$ deep, bottom not seen, ) at LS section, it was formed in the last glacial period, both the CIA value and $\mathrm{K}_{2} \mathrm{O} / \mathrm{Na}_{2} \mathrm{O}$ value are the smallest, the degree of concentration for $\mathrm{Fe}, \mathrm{Al}$ and $\mathrm{K}$ is low, the leaching degree of $\mathrm{Na}$ is the lowest. When the climate was dry and cold. it is presumed that the water level of the Yellow River in the north of the section is lowered, the flood land of the Yellow River is accumulated as the thick beach. In the meantime the plain in the north China are exposed, the coverage of vegetation is low. So, the northwest monsoon dominated the winter monsoon, in the direction of the wind blowing, a lot of sand blowing from the Yellow River Beach and the plain in the north China to Jinan, Zhangqiu, Zibo and other places, due to the southern mountains block in central shandong, it settled in the northern foot of the mountain, which become the main source of LS section.

Lt (190 160 cm deep), the transition layer, formed in the early Holocene, the CIA value and the $\mathrm{K}_{2} \mathrm{O} / \mathrm{Na}_{2} \mathrm{O}$ value starts to increase, the degree of weathering starts to be strengthened, $\mathrm{Fe}, \mathrm{Al}$ and $\mathrm{K}$ starts to concentrate,
$\mathrm{Na}$ also has a certain leaching. The weathering is strengthened, the concentration degree of $\mathrm{Fe}, \mathrm{Al}$ and $\mathrm{K}$ is still low, the monsoon is transformed.

In the layer of $\mathrm{S}_{0}(160 \sim 50 \mathrm{~cm})$, Both the CIA value and the $\mathrm{K}_{2} \mathrm{O} / \mathrm{Na}_{2} \mathrm{O}$ reach the maximum value of the whole section, the leaching of $\mathrm{Na}$ is also stronger, the concentration degree of $\mathrm{Fe}, \mathrm{Al}$ and $\mathrm{K}$ is also the maximum, it explains that the weathering degree reaches the maximum value of the whole section, when we enter the middle Holocene, the monsoon of winter is gradually weakened, the soil is the strongest.At this time the winter monsoon is weakest, the summer monsoon takes the advantage, and therefore, the effect of dust storm is reduced in an apparent way. While in the last interglacial period and the Holocene epoch, the pollen records show that the west bank of Bohai and the Laizhou Bay are the landscapes of broad leaved forest meadow or the swamp meadow, it does not have the condition for the supply dust (Cao, et al. 1987). Therefore, it can be initially presumed that the Holocene epoch, especially the formation of $\mathrm{S}_{0}$ when the monsoon of winter is the weakest, basically all the materials on the LS section are from the flood land of the Yellow River in the north of the research area and the sedimentation of the plain in the north China.

$\mathrm{L}_{0}(50 \sim 0 \mathrm{~cm})$, is the accumulation layer of the modern wind dust, it formed in the late Holocene, the CIA value and the $\mathrm{K}_{2} \mathrm{O} / \mathrm{Na}_{2} \mathrm{O}$ value are reduced all in a sudden, the weathering is weakened, the concentration degree of $\mathrm{Fe}, \mathrm{Al}$ and $\mathrm{K}$ is still low, the climate is deteriorating.

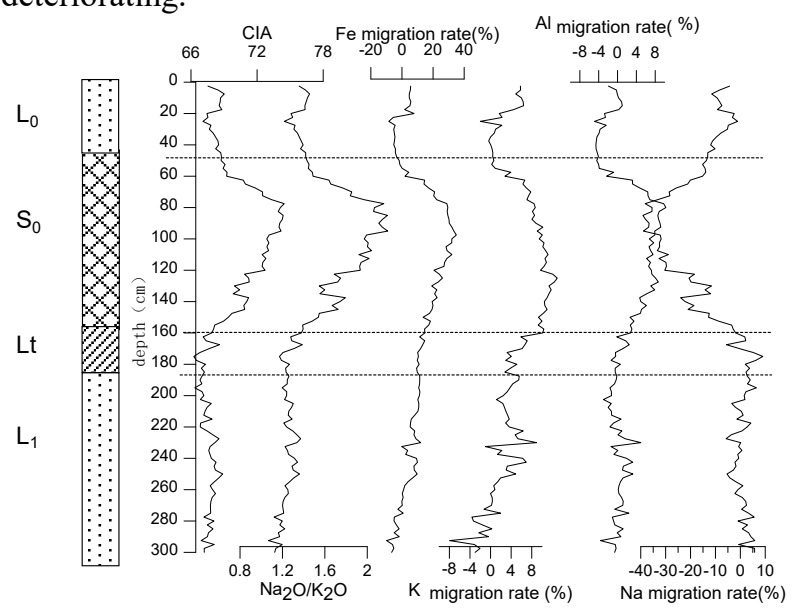

Fig. 7. Major element ratios and Migration ratios of major elements at LS profile in Shandong 


\section{Conclusion}

This article systematically analyse the composition of the major elements in the LS Loess section in the central Shandong mountainous regions and compares it with the YHC section of the Loess Plateau to study the geochemical characteristics and the material source of LS loess. It is discovered as that:

(1) The average chemical composition in the LS section in Shandong province is very similar to the composition of the $\mathrm{YHC}$ section which is the typical Aeolian, $\mathrm{SiO}_{2}, \mathrm{Al}_{2} \mathrm{O}_{3}, \mathrm{CaO}$ and $\mathrm{Fe}_{2} \mathrm{O}_{3}$ in the composition takes the absolute advantage, the average content of the four reaches $82.77 \%$.

(2) The CIA, $\mathrm{Na}_{2} \mathrm{O} / \mathrm{K}_{2} \mathrm{O}$ and $\mathrm{Al}_{2} \mathrm{O}_{3}-\mathrm{CaO}+\mathrm{Na}_{2} \mathrm{O}$ $\mathrm{K}_{2} \mathrm{O}$ triangles consistently discloses that the LS section belongs to the medium weathering, the weathering degree is higher than that of the YHC section on the Loess Plateau but it is still at the stage of dropping $\mathrm{Na}$, $\mathrm{Ca}$, it has not entered the stage of dropping $\mathrm{K}, \mathrm{Si}$. The activity sequence for the elements is $\mathrm{Ca}>\mathrm{Na}>\mathrm{Mg}>\mathrm{Si}$ $>\mathrm{Al}>\mathrm{K}>\mathrm{Fe}$, the activity capability is $\mathrm{LS}>\mathrm{YHC}$.

(3) The ratio of $\mathrm{TiO}_{2} / \mathrm{Al}_{2} \mathrm{O}_{3}$ and $\mathrm{K}_{2} \mathrm{O} / \mathrm{Al}_{2} \mathrm{O}_{3}$ for the index of material source is clearly distinguished the LS loess and the YHC loess, it is presumed that the loess in the LS section and the Loess Plateau have different wind force transportation system, It is not the result of dust storm direct from the northwest of china, otherwise, the Yellow River sedments and the North China Plain Material nearby may be its main sources when it was colder and drier during the glacial period.

(4) CIA and $\mathrm{K}_{2} \mathrm{O} / \mathrm{Na}_{2} \mathrm{O}$, and the migration rate of $\mathrm{Fe}, \mathrm{Al}, \mathrm{K}$ and $\mathrm{Na}$ is restored to the depositional environment of research. The winter monsoon in the late glaciation is strong and the chemical weathering is weak. In the early Holocene winter monsoon is weakened and the chemical weathering is enhanced. In the middle of Holocene, the summer monsoon dominated and the chemical weathering is strongest; in late Holocene, the climate deteriorated again, the chemical weathering is weakened.

Acknowledgement: This study was supported by National Natural Science Foundation of China (41402319,41472313,41771218,41602353), National Key Laboratory of Loess and Quaternary Geology Open Fund (SKLLQG1002), Taishan University Talent Research Fund (Y-01-2016001). Min Ding and Shuzhen Peng both are corresponding authors.

\section{References}

Z.T.Guo, S.Z.Peng, Q.Z.Hao, et al. Late Miocene-Pliocene development of Asian acidification as recorded in an eolian sequence in northern China, Global and Planetary Change, 41(2004)135-145.

C.C.Huang, J.L.Pang, H.X.Su, et al. The Ustic Isohumisol (Chernozem) distributed over the Chinese Loess Plateau: modern soil or palaeosol, Geoderma, 150(2009)344-358.

Q.Z.Hao, Z.T.Guo, Y.S.Qiao, et al. Geochemical evidence for the provenance of Middle Pleistocene loess deposits in Southern China, Quaternary Science Reviews, 29(23)(2010)3317-3326.

S.R.Taylor, S.M.McLennan. The Continental Crust: Its Composition and Evolution, London: Blackwell, (1985)277.

S.Z.Peng, Z.T.Guo. Geochemical indicator of original eolian grain size and implications on winter monsoon evolution, Science in China, Series D 44(Suppl.), (2001)261-266.

S.F.Xiong, Y.J.Zhu, R.Zhou, et al. Chemical weathering intensity and its grain-size dependence for the loess-red clay deposit of the baishui section, chinese loess plateau, the Research on the Quaternary, 28(5)(2008) 812-821.

J.Chen, Z.S.An, L.W.Liu, et al. The change for the chemical composition of the wind dust in the Loess Plateau and the chemical weathering for the inland of Asia since $2.5 \mathrm{Ma}$, China Science, Earth Science, 31(2)(2001) 136-145.

M. Ding, J.L.Pang, C.C.Huang, et al. Geochemical characteristics of major elements in holocene loesspaleosol sequence in the eastern Guanzhong Basin, Shaanxi, China, China Desert, 31(4)(2011)862-867

T.Y.Li, D.W.Mo, G.R.Zhu, et al. The geochemical characteristics and its paleo-environment significance of the invariable elements in the leoss section of Holocene in Jinnan, Geographical Research, 32(8)(2013)1411-1420.

N.Li, Q.Z.Hao, X.J.Zhang, et al. Geochemical evidence for the provenance of loess deposits in the eastern Qinling Mountains, central China, the Research on the Quaternary, 36(2)(2016)332-346.

X.S.Li, Z.Y.Han, S.Y.Yang, et al. Chemical weathering intensity and element migration features of the xiashu loess profile in zhenjiang, the Journal of Geographical Sciences, 62(11)(2007)1174-1184.

W.Zhang, Y.W.Dong, Y.Yu, et al. The weathering characteristics and its environmental significance for the loess in Liaonan, the Marine Geology and the Quaternary Geology, 33(5)(2013)163-171.

J.X.Cao, P.Y.Li, N.Shi. The loess at the group islands of Miao Dao in Shandong, China Science B edition, (10)(1987)123-127.

Z.L.Zhang. Research on the loess at the plain near the sea in the south of Bohai, Science Bulletin, 40(1)(1995)57-63.

S.L.Zhao, H.J.Yu. Shelf desertization environment in the bohai and yellow seas during the last glaclal maximum, the Research on the Quaternary, 2(1)(1996)42-44.

S.Z.Peng, Z.D.Gao, X.P.Wu, L.B.Zhang, M.Y.Liang, Y.S.Qiao. Grain - size distribution and genesis of loess in 
the Qingzhou area, shandong, Journal of Geomechanics ,13(4)(2007)315-321.

S.Z.Peng, L.J.Zhu, G.Q.Xiao, et al. Magnetostratigraphy and provenance of the Qingzhou loess in Shandong province, Journal of Arid Land, 3(3)(2011)184-190.

S.J.Xu, X.C.Ding, Z.C.Ni. The sedimentary characteristics of Buxi loess profile in Shandong Province and their paleoclimatic and palaeoenvironment significance, the Journal of Geographical Sciences, 11(2014)1707-1717.

P.Y.Li. Late cenozoic erathem and environment vicissitudes of Miaodao archipelago, shandong province, Marine Geology and the Quaternary Geology,7(4)(1987)111-122.

M.Ding, S.Z.Peng, J.L.Pang, W.Zhang, D.D.Chen, H.J.Yang. Holocene environment change and its impacts on cultural development in the central region of Shandong province, the Notice of Soil, 42(06)(2011)1281-1287.

G.Y.Diao. $\mathrm{CaCO}_{3}$ and REE in the loess of Shandong, geology, Geochemistry, (02)(1994)98-102.

S.Z.Peng, Q.Z.Hao, L.Wang, et al. Geochemical and grainsize evidence for the provenance of loess deposits in the Central Shandong Mountains region, northern China,QuaternaryResearch(2015),http://dx.doi.org/10.101 6/j.yqres,(2016).01.005

J.S.Xu，Z.C.Ni，X.C.Ding. Geochemical characteristics of major elements of the Pingyin loess in Shandong province , Bulletin of Mineralogy;Petrology and Geochemistry ,35(2)(2016)353-359.

Z.C.Ni. The osl age for the loess on the group islands of Miao Dao, Shandong province and the discussion for the material source, Jinan: Shandong Normal University, (2015)

Z.Y.Gu. Weathering histories of chinese dust deposits base on uranium and thoriun series nuclides, $10 \mathrm{Be}$ and major elements, Beijing: Institute of Geology and Geophysics, Chinese Academy of Sciences, (1999)

Y.Wang, F.S.Wei. The element chemistry of soil environment, Beijing: China Environmental Science Press,(1995)362379, 75-86, 180-192.

S.Gallet, B.Jahn, M.Torii. Early Proterozoic climates and plate motions inferred from major element chemistry of lutites, Nature, 229(1982)715-717.

H.W.Nesbitt, G.M.Young. Early Proterozoic climates and plate motions inferred from major element chemistry of lutites, Nature, 299(1982)715-717.

H.W.Nesbitt, G.Markovics, R.C.Price. Chemical processes affecting alkalis and alkaline earths during continental weathering,Geochem Cosmochim Acta, 44(11)(1980)1659-1666.

S.M.McLennan. Weathering and global denudation, Journal of Geology, 101(1993) 295-303.

H.J.Yang. Research on the geochemical characteristics of the soil element and the evolution of the environment for the soil formation for the loess in Holocene at the Great Wall in Ningxia, Xi'an, : Shanxi Normal University, (2010)

X.Y.Yang, C.C.Huang, J.L.Pang, et al. Dust source of the Holocene loess-soil and pedogenic environmental changes in the upper Huaihe River,Journal of Geographical Sciences, 19(1)(2009)107-117. 